\title{
Lipid Rafts: Keys to Sperm Maturation, Fertilization, and Early Embryogenesis
}

\author{
Natsuko Kawano, ${ }^{1}$ Kaoru Yoshida, ${ }^{2}$ Kenji Miyado, ${ }^{1}$ and Manabu Yoshida ${ }^{3}$ \\ ${ }^{1}$ Division of Gamete and Reproductive Biology, National Research Institute for Child Health and Development, \\ 2-10-1 Okura, Setagaya, Tokyo 157-8535, Japan \\ ${ }^{2}$ Biomedical Engineering Center, Toin University of Yokohama, Yokohama 225-8502, Japan \\ ${ }^{3}$ Misaki Marine Biological Station, Graduate School of Science, University of Tokyo, Miura, Kanagawa 238-0225, Japan \\ Correspondence should be addressed to Natsuko Kawano, nkawano@nch.go.jp
}

Received 14 September 2010; Revised 17 November 2010; Accepted 17 December 2010

Academic Editor: Angel Catala

Copyright (๑) 2011 Natsuko Kawano et al. This is an open access article distributed under the Creative Commons Attribution License, which permits unrestricted use, distribution, and reproduction in any medium, provided the original work is properly cited.

Cell membranes are composed of many different lipids and protein receptors, which are important for regulating intracellular functions and cell signaling. To orchestrate these activities, the cell membrane is compartmentalized into microdomains that are stably or transiently formed. These compartments are called "lipid rafts". In gamete cells that lack gene transcription, distribution of lipids and proteins on these lipid rafts is focused during changes in their structure and functions such as starting flagella movement and membrane fusion. In this paper, we describe the role of lipid rafts in gamete maturation, fertilization, and early embryogenesis.

\section{Introduction}

Fertilization is the process in which 2 different gamete cells, a sperm and an oocyte, unite to produce a zygote. For fertilization to be successful, these gamete cells must differentiate and activate specific signaling pathways. For example, after sperm has differentiated completely, various extracellular factors such as epididymosomes and albumin alter the structure and function of the plasma membrane of the sperm. In addition, in terminally differentiated gamete cells, various sterols, sphingolipids, glycolipids, and glycosylphosphatidylinositol(GPI-) anchored proteins are localized on cell membrane microdomains that are called lipid rafts. Lipid raft components are often examined by using detergent-resistant membrane domains (DRMs), which enrich these components so that their distributions and functions can be visualized on the cell surface by using putative raft markers $[1,2]$. Since lipid rafts in gametes contain signaling proteins that regulate intracellular functions and cell signaling, these domains are important for sperm maturation, fertilization, and early embryogenesis $[3,4]$. In this paper, we discuss the role of lipid rafts in reproductive biology.

\section{Sperm Maturation and Membrane Modification}

Sperm are highly differentiated haploid cells with a head and a tail (flagellum) [5]. The head consists of a nucleus, an acrosome, and a small amount of cytoplasm, while the tail consists of a motility apparatus, mitochondria, an axoneme, and cytoskeletal structures. Although these structures are necessary for sperm to swim and fertilize oocytes, these structures are not functional after spermatogenesis until the plasma membrane is modified during epididymal transit (Figure 1(a)) [6]. In mammals, the sperm mature in the epididymis; however, in other animals, sperms mature in the spermiduct [7]. Previous studies have demonstrated that the modifications of the sperm plasma membrane that occur during epididymal transit include changes in its lipid and 
(a)

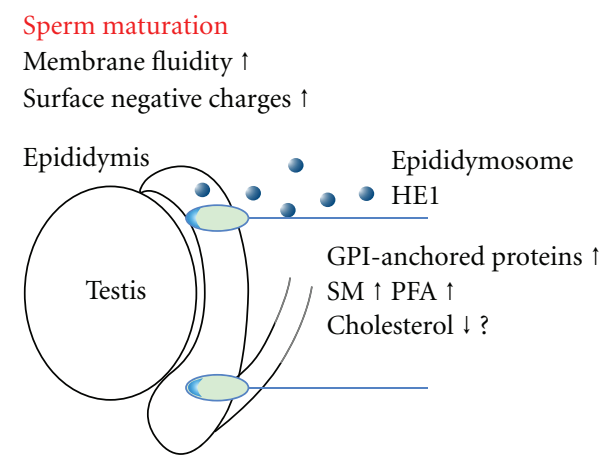

(b)

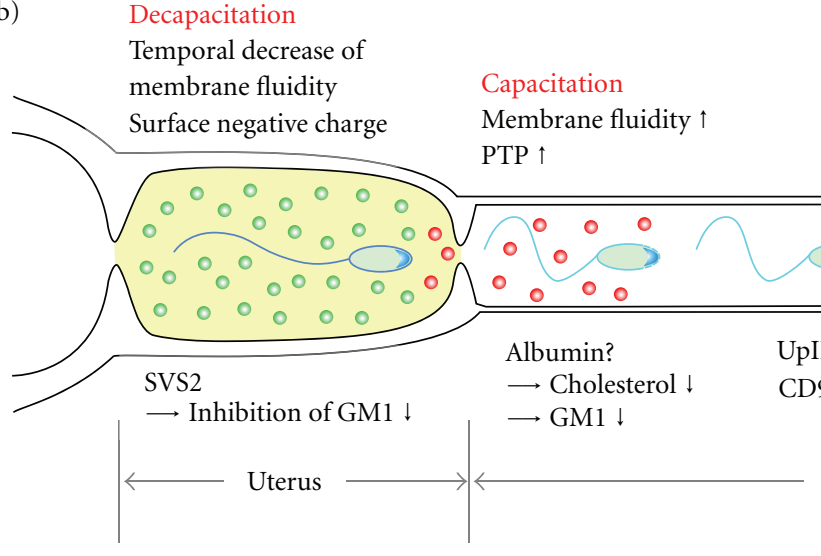

(c)

Fertilization

Cell-recognition Compaction Adhesion Fusion Pluripotency (d)

Cell fate

Pluripotency

FIGURE 1: Schematic of lipid rafts in gamete formation, function, fertilization, and early embryogenesis. (a) Sperm mature, gaining motility and fertilizing abilities, during epididymis transit. The extracellular factors, epididymosome and HE1, dynamically change the components of the sperm plasma membrane. (GPI, glycosylphoshphatidylinositol; SM, sphingomyelin; PFA, polyunsaturated membranous fatty acids). (b) Ejaculated sperm are temporally bound to SVS2 (decapacitation). SVS2 binds to GM1 of the sperm head in the uterus, resulting in the inhibition of the fertilizing ability of sperm. Subsequently, the sperm that migrate to the oviduct undergo capacitation. Capacitation causes an efflux of cholesterol and $\mathrm{G}_{\mathrm{M} 1}$ from the plasma membrane and an increase of membrane fluidity and protein tyrosine phosphorylation (PTP). (c) Sperm recognize and adhere to UpIII/UpIb of Xenopus oocyte and fuse with CD9/CD81 of murine oocyte plasma membrane. These molecules are enriched in lipid rafts, and oocytes treated with cyclodextrin prevent the sperm from fertilization. (d) In early embryogenesis, SSEAs are colocalized with cholesterol and $\mathrm{G}_{\mathrm{M} 1}$ plays an important role in the compaction of an embryo, leading to the decision of cell fate and its pluripotency.

protein composition, modifications of surface proteins, and increased total negative charge of the extracellular surface $[8,9]$.

Electron microscopy studies showed that the epididymal lumen contained membranous vesicles that which called epididymosomes [10-12]. These vesicles, which are particularly rich in sphingomyelin (SM) and arachidonic acids, are secreted via apocrine secretion. In addition, twodimensional gel electrophoresis and liquid chromatographyquadrupole time-of-flight (LC-QToF) analyses show that epididymosomes contain endoplasmin (heat shock protein $90 \beta 1$; Hsp90 $\beta 1$ ), $70 \mathrm{kDa}$ heat shock protein 5 , chaperones, and other exosomes [13-16]. In addition, integral membrane proteins, such as GPI-anchored proteins, also are associated with epididymosomes. Several GPI-anchored proteins in epididymosomes have been found in the mature sperm of various animals. For example, HE5 (CD52) is found in human sperm [17], SPAM 1 and hyaluronidase are present in mouse sperm [18-21], and P26h [22] and P25b [23] are found in hamsters and bulls, respectively [24]. In addition, epididymosomes localize to the sperm membrane during epididymal transit and contribute to the formation of various membrane structures such as lipid rafts in sperm [25]. Furthermore, in sperm membrane lipids, the percentage composition of both SM and various polyunsaturated fatty acids, which are mainly arachidonic, docosapentaenoic, and docosahexaenoic acids, increases throughout the epididymal tract [12].

Six genes, known as HE1-HE6, are expressed specifically in the human epididymis [26-28]. Mutations in HE1 cause Niemann-Pick type C2 (NPC2) disease, a fatal neurovisceral disorder that is characterized by the accumulation of cholesterol in lysosomes [29]. HE1 is a small, soluble glycoprotein with 132 amino acids that binds to cholesterol, but not to cholesterol derivatives that have hydrophilic substitutions on their isooctyl side chains [29-32]. Xu et al. [33] determined the X-ray crystallographic structure of bovine NPC2 protein complexed with cholesterol sulfate. Together, these studies showed that HE1 binds to cholesterol in vitro and may regulate the cholesterol content in sperm 
throughout the epididymal tract. However, other studies have demonstrated that the ratio of total phospholipid to total cholesterol does not change during epididymal transit $[12,34]$. Previously, we used filipin as a cytochemical probe for membrane cholesterol in the sperm plasma membrane during epididymal maturation (Figure 2). Our results show that the filipin signal decreased at the post-acrosomal region during epididymal transit. Similar pattern of filipin was observed in boar sperm [35]. Previous studies have shown that the rate of pregnancy in humans decreases as the amount of time between a vasectomy and its reversal increases [3638]. In addition, sperm from men who have undergone vasectomy reversal have higher levels of HE1, cholesterol, and ganglioside $\mathrm{G}_{\mathrm{M} 1}$ compared with sperm from fertile men who have not had vasectomy [39]. These findings suggest that HE1 regulates the amount or localization of sperm lipid rafts in the epididymis, which produces mature sperm.

Several studies have shown that modification of SM, polyunsaturated fatty acids, cholesterol, and $\mathrm{G}_{\mathrm{M} 1}$ changes the fluidity of sperm membranes and the composition of lipid rafts. For example, lipid diffusion in the plasma membrane of mouse sperm increased significantly during their transition from the caput epididymis to the cauda epididymis [40]. Moreover, Nishio et al. [41] reported that pheochromocytoma PC12 cells that overexpress $G_{M 1}$ did not exhibit any neurite formation, even after stimulation with nerve growth factor (NGF). Furthermore, increased expression of $\mathrm{G}_{\mathrm{M} 1}$ reduces membrane fluidity, disorders the lipid raft, and changes the intracellular localization of NGF receptors and related signaling molecules [41]. Further studies are needed to elucidate the mechanisms and molecules that promote sperm maturation in the epididymis.

\section{Sperm Lipid Rafts and Fertility}

After maturing in the epididymis, sperm are able to swim and fertilize an oocyte (Figure 1(b)). In invertebrates that reproduce by external fertilization, sperm are usually capable of fertilization immediately after they become motile. In contrast, in mammals that reproduce by internal fertilization, sperm are unable to fertilize oocytes immediately after they can swim. Instead, sperm acquire this ability after moving to the uterus and remaining for an appropriate period of time $[42,43]$. The biochemical process that confers this ability to sperm is called "capacitation." During sperm capacitation, protein tyrosine phosphorylation occurs along with hyperactivated flagellar beating; further, the acrosome reaction is induced, and the sperm penetrates the zona pellucida (ZP) and finally binds and fuses with the oocyte. In addition, the organization of membrane proteins and lipids changes significantly [44-48]. In vitro, capacitation requires a high concentration of albumin in culture medium to decrease the sperm cholesterol/phospholipid ratio [49, 50]. Fluorescent and electron microscopic studies have shown that a combination of bicarbonate and albumin promotes membrane distribution and cholesterol efflux [35, 51, 52]. Albumin also decreases the amount of sialic acid, ganglioside, and triglyceride in the sperm plasma membrane
[49]. In addition, methyl- $\beta$-cyclodextrin (MBCD) promotes sperm capacitation in vitro, by decreasing the amount of cholesterol in the plasma membrane and disrupting lipid rafts; however, the critical concentration of MBCD should be considered [53-56]. The strong MBCD treatment also reveals some proteins that are involved in capacitation-dependent processes and ZP binding [57]. The physiological relevance of raft reordering in the sperm surface is to create protein complexes involved in $\mathrm{ZP}$ binding $[58,59]$.

Cholera toxin subunit B (CTB), which binds to ganglioside $G_{M 1}$ with a high affinity, has been widely used as a reporter of the distribution of lipid rafts and to study the CTB-binding pattern of sperm in both in vitro and in vivo conditions. We, along with several other research groups, also have developed methods to investigate the distribution of $G_{M 1}$ in fixed sperm. These studies have revealed that $G_{M 1}$ expression is significantly altered during sperm capacitation and the acrosome reaction [60-62]. In contrast, the CTBbinding pattern of sperm is variable and depends on their fixation conditions [63]. In living sperm, Selvaraj et al. [64] demonstrated that the cyclodextrin treatment does not change the distribution of $\mathrm{G}_{\mathrm{M} 1}$ in mouse or bovine sperm. However, the use of specific fixation conditions induced stimulus-specific patterns of $\mathrm{G}_{\mathrm{M} 1}$ distribution. Specifically, in mouse sperm, $\mathrm{G}_{\mathrm{M} 1}$ was broadly localized from the postacrosomal region to throughout the sperm head. Shadan et al. [61] showed that the distribution of $\mathrm{G}_{\mathrm{M} 1}$ in boar sperm changes sequentially, from the tail to the head, during MBCD-mediated capacitation. One of our previous studies also demonstrated the CTB- binding pattern in murine sperm in physiological conditions [62]. Briefly, ejaculated sperm were collected from the female mice when the sperm were first detected in their oviducts (approximately 3 hours after copulation). Their reproductive tracts were divided into 4 parts, namely, the oviduct, uterine region near the oviduct, uterine region near the cervix, and vagina. While the sperm migrated from the uterus to the oviduct, CTB fluorescence was lost from the postacrosomal region. In addition, $G_{M 1}$ interacted with seminal vesicle secretion 2 (SVS2), which is secreted from seminal vesicles and inhibits sperm capacitation. Since SVS2 is a highly basic protein, this interaction depends on its charge. In addition, CTB also inhibited sperm capacitation. Increasing evidence suggests that sperm capacitation is regulated by the distribution of $\mathrm{G}_{\mathrm{M} 1}$ or its charge on the sperm plasma membrane. However, staining pattern by CTB is not consistent with that by other probes, such as lysenin and antibody against Thy$1.2[65,66]$. Lysenin and the antibody have high affinities for sphingomyelin and GPI-anchored protein enriched in the DRM fractions, respectively [65]. Further investigation is needed to elucidate the localization of lipid rafts more precisely.

Some lipid rafts are found in cell surface invaginations called caveolae. These invaginations are formed from lipid rafts by polymerization of caveolins, which are palmitoylated integral membrane proteins that bind to cholesterol with high affinity $[67,68]$. Previous studies have demonstrated that caveolin-1 and -2 are enriched in the Triton X-100insoluble membrane fraction of mature sperm and localize 




Cauda epididymal sperm

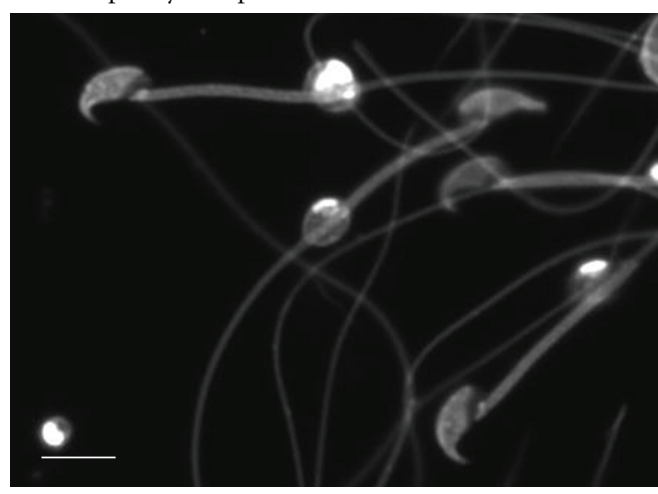

(a)
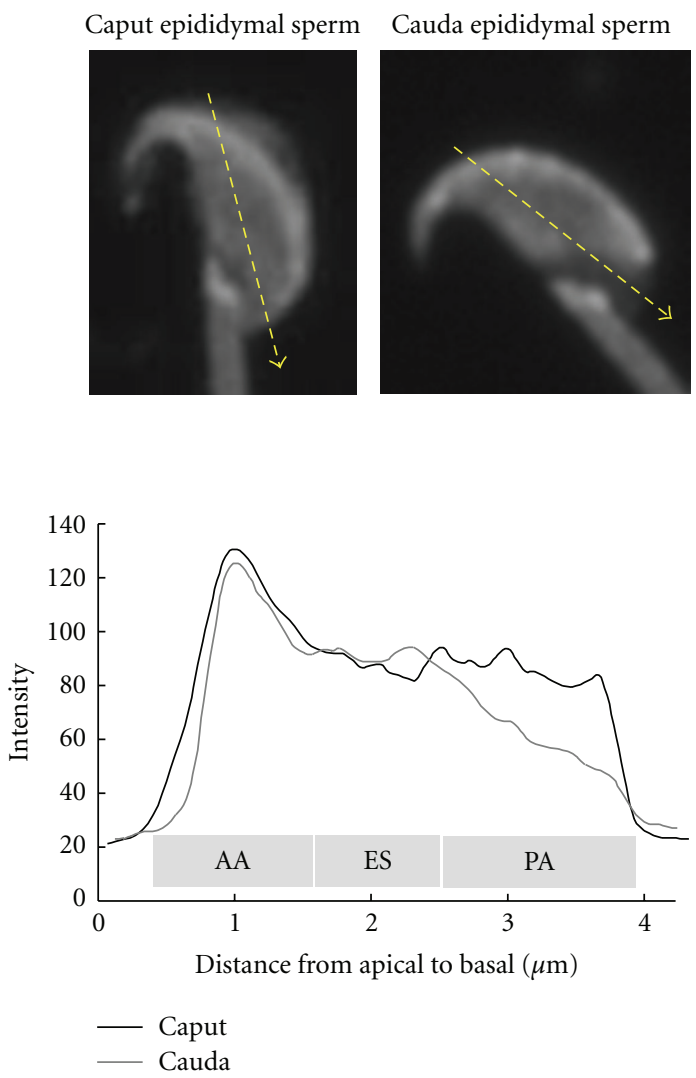

(b)

FIGURE 2: Distribution of cholesterol during sperm maturation in murine epididymis. (a) Sperm collected from caput epididymis reveal filipin signal on the whole head. After epididymal transit (cauda epididymis), the signal is not detected in the postacrosomal region (PA). Scale bar $=5 \mu \mathrm{m}$. (b) Densitometric analysis shows a significant decrease of filipin signal at the postacrosomal region. AA, apical acrosome; ES, equatorial segment; PA, postacrosomal.

to the acrosomal membrane $[69,70]$. Since these caveolins disappear after the completion of the acrosome reaction, they are thought to regulate the acrosome reaction. However, caveolin-1-and -2-null mice are fertile, and the distribution of $\mathrm{G}_{\mathrm{M} 1}$ in caveolin-1-deficient mouse sperm is comparable to that in wild-type mouse sperm $[63,71,72]$. These findings suggest that caveolae are not required for the presence of lipid rafts in the acrosomal membrane and fertilization of mouse sperm. However, several other studies indicate that lipid rafts in the apical ridge head area of sperm have affinity for the $\mathrm{ZP}$ $[57,59]$. Since the $\mathrm{ZP}$ is involved in the acrosome reaction, the function of lipid rafts in this reaction is still controversial.

\section{Oocyte Lipid Rafts and Fertility}

In general, sex hormones stimulate the continuation of the first meiotic division of oocytes. However, in some animals, this occurs after the oocyte is released from an inhibitory environment. In both vertebrates and invertebrates, the first meiotic division of oocytes is asymmetric, which results in the formation of a relatively large oocyte and small polar bodies. During meiotic arrest, oocytes are fertilized by sperm, and then the second meiotic division is completed.
The activation of oocytes upon fertilization is a $\mathrm{Ca}^{2+}$ dependent process in all animals [73, 74]. Furthermore, intracellular $\mathrm{Ca}^{2+}\left(\left[\mathrm{Ca}^{2+}\right]_{i}\right)$ is a key regulator of many cellular functions [75]. In oocytes, increased $\left[\mathrm{Ca}^{2+}\right]_{i}$ stimulates the continuation of the second meiotic division and formation of the second polar body, followed by formation of male and female pronuclei $[47,75]$. The signaling pathway that regulates this increase in $\left[\mathrm{Ca}^{2+}\right]_{i}$ is highly conserved among species [76]. In this pathway, phospholipase C(PLC-) dependent production of inositol 1,4,5-triphosphate $\left(\mathrm{IP}_{3}\right)$ triggers the increase in $\left[\mathrm{Ca}^{2+}\right]_{i}$, which propagates from the endoplasmic reticulum. In contrast, the binding of sperm to the oocyte plasma membrane is species specific. Currently, there are 2 hypotheses about how a sperm binds and activates an oocyte, namely, a transmembrane receptor mechanism that involves $G$ proteins and a soluble sperm factor mechanism [77]. Xenopus oocytes have a G proteincoupled sperm receptor that activates PLC on the plasma membrane (Figure 1(c)). In addition, lipid-raft-associated proteins, such as uroplakin III (xUPIII) and its tetraspaninbinding partner uroplakin $\mathrm{Ib}$ (UPIb), are involved in the sperm-oocyte membrane interaction and subsequent oocyte activation. Specifically, xUPIII is cleaved by sperm protease 

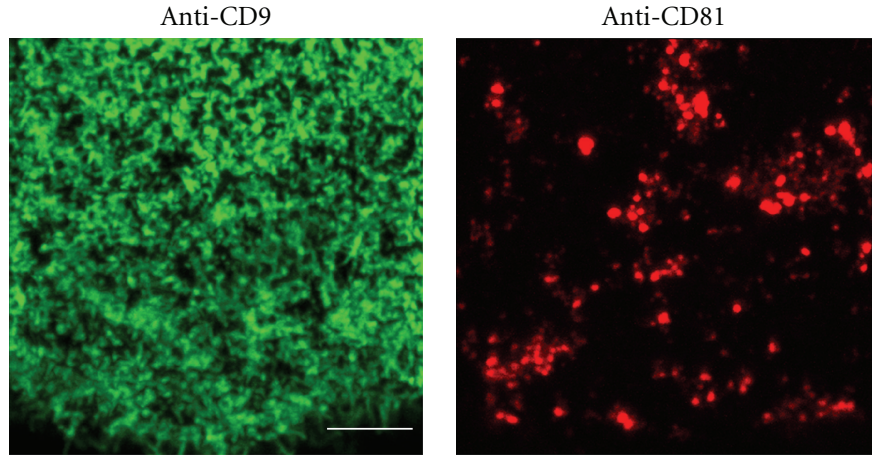

(a)
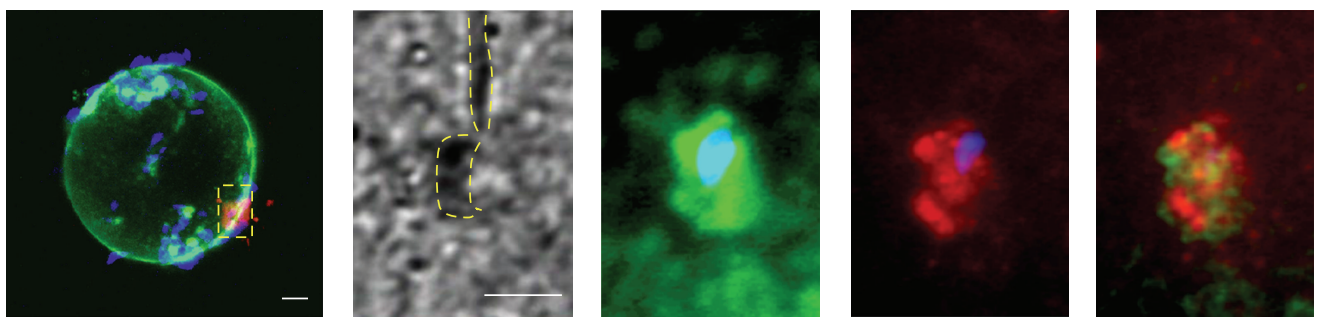

(b)
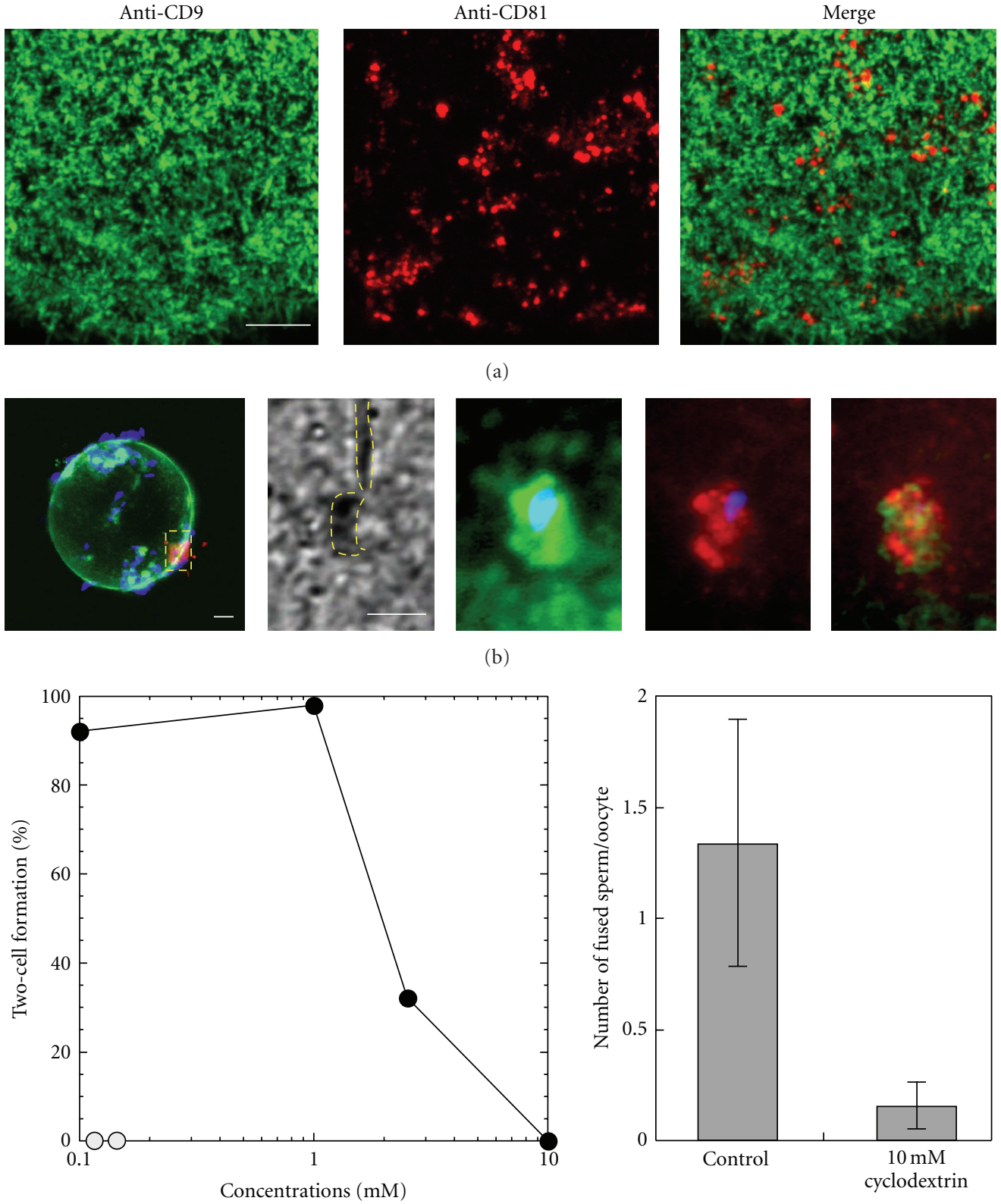

Cyclodextrin

Filipin 
lipid raft-like microdomains in A431 and HT1080 cell lines [83]. Female CD9 knockout mice are infertile; although they produce oocytes that mature normally, these oocytes cannot fuse with sperm [81]. CD81, which has a similar structure and function as CD9, also is involved in gamete fusion. However, the effects of deleting CD81 are less dramatic than those of deleting CD9 [82, 84]. The expression level of CD9 is not affected by a deficiency of CD81 in murine oocytes and vice versa. Both CD9 and CD81 are localized on the surface of murine oocytes (Figure 3(a)). However, their distributions were completely different. As previously described [85], CD9 was expressed on the oocyte microvilli. Whereas CD81 was distributed in microdomain-like structures between microvilli that expressed CD9. However, both CD9 and CD81 were concentrated at the sperm attachment site (Figure 3(b)). Cyclodextrin, a lipid-raft disruptor, inhibited sperm-oocyte fusion and decreased the percentage of twocell formation in a dose-dependent manner (Figure 3(c)). Similarly, filipin had the same effect on the oocyte plasma membrane. As a result, it is likely that CD9 and CD81 are important for coordinating the sperm-oocyte fusion process in mice.

\section{Lipid Rafts in Early Development}

After fertilization, the zygote divides into a blastocyst that can be implanted into the uterus in mammals. At the 8-cell stage, a murine embryo undergoes compaction to form polarized morulae (Figure 1(d)). This process involves substantial changes in cellular organization. Consequently, positional and functional differences occur among the blastocyst cells [86]. FILIA-MATER complexes localize asymmetrically in the apical cytocortex of 2-cell embryos due to their absence near cell-cell contact [87]. Although this asymmetry is reversible when the blastomeres of 2- and 4-cell embryos are separated, FILIA-MATER complexes are detected at the apical subcortex of "outer" but not "inner" cells of morulae. These findings indicate that the plasticity of the localization of FILIA-MATER complexes may reflect the cell fate determination of preimplantation mouse embryos. The outer cells of the morulae become the mural trophectoderm while the inner cells form the inner cell mass (ICM) of the blastocyst. Originally, embryonic stem (ES) cells were isolated from the ICM of the blastocyst and were shown to be pluripotent and self-renewing. The studies about FILIA-MATER complexes and ES cells suggest that cell-cell adhesion that results from compaction may be responsible for pluripotency.

Many cell-surface antigens that are markers of pluripotency have been identified in the ICM, ES cells, and embryonic carcinoma cells. The most common marker of murine ES cells is stage-specific embryonic antigen (SSEA)-1. The expression of this antigen changes dramatically in preimplantation mouse embryos. Specifically, SSEA-1 is highly expressed in the morula stage, suppressed after compaction, and then expressed only in the ICM of the blastocyst [88]. The Lewis ${ }^{\mathrm{x}}$ epitope of SSEA-1 $(\mathrm{Gal} \beta 1 \rightarrow 4(\mathrm{Fuc} \alpha 1 \rightarrow 3)$ GlcNAc $\beta 1 \rightarrow 3 \mathrm{Gal})$ also is found on glycosphingolipids and glycoproteins [89-91]. Mouse blastomeres and embryonic carcinoma cells identify each other and aggregate by recognizing this epitope $[92,93]$. Similarly, SSEA-3 and -4 are common markers of human pluripotent stem cells and are highly expressed before the morula stage but decline afterwards [94]. The SSEA-3 and -4 epitopes are unique globo-series glycosphingolipids, namely, R-3GalNAc $\beta 1 \rightarrow$ $3 \mathrm{Gal} \alpha 1 \rightarrow 4 \mathrm{R}^{\prime}$ and NeuAc $\alpha 2 \rightarrow 3 \mathrm{Gal} \beta 1 \rightarrow 3$-GalNAc $\beta 1 \rightarrow$ $3 \mathrm{Gal} \alpha 1 \rightarrow 4 \mathrm{R}^{\prime}$, respectively [95-97]. The SSEA-4 epitope is found in the lipid rafts of $A C H N$, a human renal cancer cell line [98]. In viable murine embryos, an antiSSEA-4 antibody detects SSEA-4 over the entire membrane surface, with some accumulation at the interface between blastomeres [99]. A similar pattern of localization also was also observed with CTB staining [100]. Because other SSEAs are homologous to glycosphingolipids and share similar chemical properties, they are also likely to be enriched in lipid-rafts. SSEA-1 is colocalized with adhesion-related proteins, such as CD9, ICAM-1, and PECAM-1, in the contact regions of murine embryos and ES cells [101]. These proteins also are lipid raft-associated proteins [102-104] that are distributed in a way similar to SSEA-4. Collectively, these findings suggest that SSEA-1, -3, -4 are localized in lipid rafts, are involved in cell-cell adhesion, and may contribute to the pluripotency of mouse ES cells.

In addition to cell adhesion, lipid rafts play an important role in cytokinesis [105], which is a complex process that involves dynamic cortical rearrangement. Surprisingly, clathrin mutations that affect endocytosis cause defects in cytokinesis in many organisms $[106,107]$. Feng et al. [108] showed that clathrin and caveolae are localized at the cleavage furrow in zebrafish blastomeres. In embryos, MBCD inhibits endocytosis and prevents normal cytokinesis. Ganglioside $\mathrm{G}_{\mathrm{M} 1}$, cholesterol, and tyrosine-phosphorylated proteins also have been found in the cleavage furrow and plane of sea urchin embryos [109]. In these embryos, DRMs contain Src and PLC $\gamma$, which are tyrosine phosphorylated at the site of cytokinesis. Furthermore, activation of these enzymes is required for furrow progression. These studies suggest that caveolae and lipid rafts contribute to cytokinesis in early developmental embryos.

\section{Acknowledgments}

The authors thank Y. U. Katagiri, B. Sato, and T. Hibino for their critical advice and encouragement to complete this paper. Natsuko Kawano is supported by a Research Fellowship from the Japan Society for the Promotion of Science for Young Scientists (no. 5104). This work was partly supported by grants-in-aid from the Ministry of Education, Science, Technology, Sports, and Culture of Japan.

\section{References}

[1] D. A. Brown and J. K. Rose, "Sorting of GPI-anchored proteins to glycolipid-enriched membrane subdomains during transport to the apical cell surface," Cell, vol. 68, no. 3, pp. 533-544, 1992. 
[2] T. Harder, P. Scheiffele, P. Verkade, and K. Simons, "Lipid domain structure of the plasma membrane revealed by patching of membrane components," Journal of Cell Biology, vol. 141, no. 4, pp. 929-942, 1998.

[3] N. Tanphaichitr, J. Smith, S. Mongkolsirikieart, C. Gradil, and C. A. Lingwood, "Role of a gamete-specific sulfoglycolipid immobilizing protein on mouse sperm-egg binding," Developmental Biology, vol. 156, no. 1, pp. 164-175, 1993.

[4] E. Maehashi, C. Sato, K. Ohta et al., "Identification of the sea urchin $350-\mathrm{kDa}$ sperm-binding protein as a new sialic acid-binding lectin that belongs to the heat shock protein 110 family: implication of its binding to gangliosides in sperm lipid rafts in fertilization," Journal of Biological Chemistry, vol. 278, no. 43, pp. 42050-42057, 2003.

[5] K. Toshimori, "Introduction," in Dynamics of the Mammalian Sperm Head, H. W. Korf, Ed., vol. 204 of Advances in Anatomy, Embryology and Cell Biology, pp. 5-6, Springer, New York, NY, USA, 2009.

[6] M. C. Orgebin-Crist, "Sperm maturation in rabbit epididymis," Nature, vol. 216, no. 5117, pp. 816-818, 1967.

[7] M. Yoshida, N. Kawano, and K. Yoshida, "Control of sperm motility and fertility: diverse factors and common mechanisms," Cellular and Molecular Life Sciences, vol. 65, no. 21, pp. 3446-3457, 2008.

[8] R. Sullivan, "Interaction between sperm and epididymal secretory proteins," in The Male Gamete: From Basic to Clinical Applications, C. Gagnon, Ed., pp. 130-136, Cache River Press, Vienna, Ill, USA, 1999.

[9] P. Cuasnicu, D. Cohen, D. Ellerman, D. Busso, V. DaRos, and M. Morgenfeld, "Changes in sperm proteins during epididymal maturation," in The Epididymis: From molecules to Clinical Practice, B. H. Robaire, Ed., pp. 389-404, Plenum Press, New-York, NY, USA, 2002.

[10] R. Yanagimachi, Y. Kamiguchi, and K. Mikamo, "Maturation of spermatozoa in the epididymis of the Chinese hamster," American Journal of Anatomy, vol. 172, no. 4, pp. 317-330, 1985.

[11] R. Sullivan, F. Saez, J. Girouard, and G. Frenette, "Role of exosomes in sperm maturation during the transit along the male reproductive tract," Blood Cells, Molecules, and Diseases, vol. 35, no. 1, pp. 1-10, 2005.

[12] H. Rejraji, B. Sion, G. Prensier et al., "Lipid remodeling of murine epididymosomes and spermatozoa during epididymal maturation," Biology of Reproduction, vol. 74, no. 6, pp. 1104-1113, 2006.

[13] M. Triantafilou and K. Triantafilou, "Heat-shock protein 70 and heat-shock protein 90 associate with Toll-like receptor 4 in response to bacterial lipopolysaccharide," Biochemical Society Transactions, vol. 32, no. 4, pp. 636-639, 2004.

[14] B. Février and G. Raposo, "Exosomes: endosomal-derived vesicles shipping extracellular messages," Current Opinion in Cell Biology, vol. 16, no. 4, pp. 415-421, 2004.

[15] S. Dhungana, B. A. Merrick, K. B. Tomer, and M. B. Fessler, "Quantitative proteomics analysis of macrophage rafts reveals compartmentalized activation of the proteasome and of proteasome-mediated ERK activation in response to lipopolysaccharide," Molecular and Cellular Proteomics, vol. 8, no. 1, pp. 201-213, 2009.

[16] S. Mathivanan, H. Ji, and R. J. Simpson, "Exosomes: extracellular organelles important in intercellular communication," Journal of Proteomics, vol. 73, no. 10, pp. 1907-1920, 2010.

[17] C. H. Yeung, F. Perez-Sanchez, S. Schróter, C. Kirchhoff, and T. G. Cooper, "Changes of the major sperm maturationassociated epididymal protein HE5 (CD52) on human ejaculated spermatozoa during incubation in capacitation conditions," Molecular Human Reproduction, vol. 7, no. 7, pp. 617-624, 2001.

[18] B. M. Phelps, P. Primakoff, D. E. Koppel, M. G. Low, and D. G. Myles, "Restricted lateral diffusion of PH-20, a PIanchored sperm membrane protein," Science, vol. 240, no. 4860, pp. 1780-1782, 1988.

[19] C. D. Thaler and R. A. Cardullo, "Biochemical characterization of a glycosylphosphatidylinositol-linked hyaluronidase on mouse sperm," Biochemistry, vol. 34, no. 24, pp. 77887795, 1995

[20] H. Zhang and P. A. Martin-DeLeon, "Mouse epididymal Spam1 (PH-20) is released in the luminal fluid with its lipid anchor," Journal of Andrology, vol. 24, no. 1, pp. 51-58, 2003.

[21] P. A. Martin-DeLeon, "Epididymal SPAM1 and its impact on sperm function," Molecular and Cellular Endocrinology, vol. 250, no. 1-2, pp. 114-121, 2006.

[22] C. Legare, B. Berube, F. Boué et al., "Hamster sperm antigen P26h is a phosphatidylinositol-anchored protein," Molecular Reproduction and Development, vol. 52, no. 2, pp. 225-233, 1999.

[23] G. Frenette and R. Sullivan, "Prostasome-like particles are involved in the transfer of P25b from the bovine epididymal fluid to the sperm surface," Molecular Reproduction and Development, vol. 59, no. 1, pp. 115-121, 2001.

[24] R. Sullivan, G. Frenette, and J. Girouard, "Epididymosomes are involved in the acquisition of new sperm proteins during epididymal transit," Asian Journal of Andrology, vol. 9, no. 4, pp. 483-491, 2007.

[25] G. Frenette, J. Girouard, and R. Sullivan, "Comparison between epididymosomes collected in the intraluminal compartment of the bovine caput and cauda epididymidis," Biology of Reproduction, vol. 75, no. 6, pp. 885-890, 2006.

[26] C. Kirchloff, C. Osterhoff, I. Habben, and R. Ivell, "Cloning and analysis of mRNAs expressed specifically in the human epididymis," International Journal of Andrology, vol. 13, no. 2, pp. 155-167, 1990.

[27] C. Kirchhoff, N. Krull, I. Pera, and R. Ivell, "A major mRNA of the human epididymal principal cells, HE5, encodes the leucocyte differentiation CDw52 antigen peptide backbone," Molecular Reproduction and Development, vol. 34, no. 1, pp. 8-15, 1993.

[28] C. Osterhoff, R. Ivell, and C. Kirchhoff, "Cloning of a human epididymis-specific mRNA, HE6, encoding a novel member of the seven transmembrane-domain receptor superfamily," DNA and Cell Biology, vol. 16, no. 4, pp. 379-389, 1997.

[29] N. Okamura, S. Kiuchi, M. Tamba et al., "A porcine homolog of the major secretory protein of human epididymis, HE1, specifically binds cholesterol," Biochimica et Biophysica Acta, vol. 1438, no. 3, pp. 377-387, 1999.

[30] N. Friedland, H. L. Liou, P. Lobel, and A. M. Stock, "Structure of a cholesterol-binding protein deficient in Niemann-Pick type C2 disease," Proceedings of the National Academy of Sciences of the United States of America, vol. 100, no. 5, pp. 2512-2517, 2003.

[31] D. C. Ko, J. Binkley, A. Sidow, and M. P. Scott, "The integrity of a cholesterol-binding pocket in Niemann-Pick C2 protein is necessary to control lysosome cholesterol levels," Proceedings of the National Academy of Sciences of the United States of America, vol. 100, no. 5, pp. 2518-2525, 2003.

[32] R. E. Infante, M. L. Wang, A. Radhakrishnan, J. K. Hyock, M. S. Brown, and J. L. Goldstein, "NPC2 facilitates bidirectional transfer of cholesterol between NPC1 and lipid bilayers, a step in cholesterol egress from lysosomes," Proceedings of the 
National Academy of Sciences of the United States of America, vol. 105, no. 40, pp. 15287-15292, 2008.

[33] S. Xu, B. Benoff, H. L. Liou, P. Lobel, and A. M. Stock, "Structural basis of sterol binding by NPC2, a lysosomal protein deficient in Niemann-Pick type C2 disease," Journal of Biological Chemistry, vol. 282, no. 32, pp. 23525-23531, 2007.

[34] M. I. Aveldaño, N. P. Rotstein, and N. T. Vermouth, "Lipid remodelling during epididymal maturation of rat spermatozoa. Enrichment in plasmenylcholines containing long-chain polyenoic fatty acids of the n-9 series," Biochemical Journal, vol. 283, no. 1, pp. 235-241, 1992.

[35] F. M. Flesch, J. F. H. M. Brouwers, P. F. E. M. Nievelstein et al., "Bicarbonate stimulated phospholipid scrambling induces cholesterol redistribution and enables cholestrol depletion in the sperm plasma membrane," Journal of Cell Science, vol. 114, no. 19, pp. 3543-3555, 2001.

[36] A. M. Belker, A. J. Thomas, E. F. Fuchs, J. W. Konnak, and I. D. Sharlip, "Results of 1,469 microsurgical vasectomy reversals by the vasovasostomy study group," Journal of Urology, vol. 145, no. 3, pp. 505-511, 1991.

[37] M. Shannon, "Update on vasectomy," CCL Family Foundations, vol. 20, no. 4, pp. 6-7, 1994.

[38] P. N. Kolettis, L. Woo, and J. I. Sandlow, "Outcomes of vasectomy reversal performed for men with the same female partners," Urology, vol. 61, no. 6, pp. 1221-1223, 2003.

[39] C. Légaré, M. Thabet, J. L. Gatti, and R. Sullivan, "HE1/NPC2 status in human reproductive tract and ejaculated spermatozoa: consequence of vasectomy," Molecular Human Reproduction, vol. 12, no. 7, pp. 461-468, 2006.

[40] Y. Christova, P. S. James, T. G. Cooper, and R. Jones, "Lipid diffusion in the plasma membrane of mouse spermatozoa: changes during epididymal maturation, effects of $\mathrm{pH}$, osmotic pressure, and knockout of the c-ros gene," Journal of Andrology, vol. 23, no. 3, pp. 384-392, 2002.

[41] M. Nishio, S. Fukumoto, K. Furukawa et al., "Overexpressed GM1 suppresses nerve growth factor (NGF) signals by modulating the intracellular localization of NGF receptors and membrane fluidity in PC12 cells," Journal of Biological Chemistry, vol. 279, no. 32, pp. 33368-33378, 2004.

[42] M. C. Chang, "Fertilizing capacity of spermatozoa deposited into the fallopian tubes," Nature, vol. 168, no. 4277, pp. 697698, 1951.

[43] C. R. Austin, "Observations on the penetration of the sperm in the mammalian egg," Australian Journal of Scientific Research B, vol. 4, no. 4, pp. 581-596, 1951.

[44] R. Yanagimachi, "Mammalian fertilization," in The Physiology of Reproduction, E. Knobil and J. D. Neil, Eds., pp. 189317, Raven Press, New York, NY, USA, 1994.

[45] D. G. Myles and P. Primakoff, "Localized surface antigens of guinea pig sperm migrate to new regions prior to fertilization," Journal of Cell Biology, vol. 99, no. 5, pp. 16341641, 1984.

[46] R. A. P. Harrison, P. J. C. Ashworth, and N. G. A. Miller, "Bicarbonate/CO2, an effector of capacitation, induces a rapid and reversible change in the lipid architecture of boar sperm plasma membranes," Molecular Reproduction and Development, vol. 45, no. 3, pp. 378-391, 1996.

[47] F. Suzuki-Toyota, Y. Itoh, and K. Naito, "Reduction of intramembranous particles in the periacrosomal plasma membrane of boar spermatozoa during in vitro capacitation: a statistical study," Development Growth and Differentiation, vol. 42, no. 3, pp. 265-273, 2000.
[48] N. L. Cross, "Reorganization of lipid rafts during capacitation of human sperm," Biology of Reproduction, vol. 71, no. 4, pp. 1367-1373, 2004.

[49] R. A. P. Harrison and B. M. Gadella, "Bicarbonate-induced membrane processing in sperm capacitation," Theriogenology, vol. 63, no. 2, pp. 342-351, 2005.

[50] B. K. Davis, R. Byrne, and K. Bedigian, "Studies on the mechanism of capacitation: albumin-mediated changes in plasma membrane lipids during in vitro incubation of rat sperm cells," Proceedings of the National Academy of Sciences of the United States of America, vol. 77, no. 3, pp. 1546-1550, 1980.

[51] P. E. Visconti, X. Ning, M. W. Fornés et al., "Cholesterol efflux-mediated signal transduction in mammalian sperm: cholesterol release signals an increase in protein tyrosine phosphorylation during mouse sperm capacitation," Developmental Biology, vol. 214, no. 2, pp. 429-443, 1999.

[52] Y. Lin and F. W. K. Kan, "Regionalization and redistribution of membrane phospholipids and cholesterol in mouse spermatozoa during in vitro capacitation," Biology of Reproduction, vol. 55, no. 5, pp. 1133-1146, 1996.

[53] Y. H. Choi and Y. Toyoda, "Cyclodextrin removes cholesterol from mouse sperm and induces capacitation in a protein-free medium," Biology of Reproduction, vol. 59, no. 6, pp. 13281333, 1998.

[54] S. Ilangumaran and D. C. Hoessli, "Effects of cholesterol depletion by cyclodextrin on the sphingolipid microdomains of the plasma membrane," Biochemical Journal, vol. 335, no. 2, pp. 433-440, 1998.

[55] R. A. Van Gestel, J. B. Helms, J. F. H. M. Brouwers, and B. M. Gadella, "Effects of methyl- $\beta$-cyclodextrin-mediated cholesterol depletion in porcine sperm compared to somatic cells," Molecular Reproduction and Development, vol. 72, no. 3, pp. 386-395, 2005.

[56] Y. Kato, S. Shoei, and Y. Nagao, "Capacitation status of activated bovine sperm cultured in media containing methyl$\beta$-cyclodextrin affects the acrosome reaction and fertility," Zygote, vol. 23, pp. 1-10, 2010.

[57] R. A. van Gestel, I. A. Brewis, P. R. Ashton, J. B. Helms, J. F. Brouwers, and B. M. Gadella, "Capacitation-dependent concentration of lipid rafts in the apical ridge head area of porcine sperm cells," Molecular Human Reproduction, vol. 11, no. 8, pp. 583-590, 2005.

[58] R. A. van Gestel, I. A. Brewis, P. R. Ashton, J. F. Brouwers, and B. M. Gadella, "Multiple proteins present in purified porcine sperm apical plasma membranes interact with the zona pellucida of the oocyte," Molecular Human Reproduction, vol. 13, no. 7, pp. 445-454, 2007.

[59] N. Tanphalchitr, E. Carmona, M. B. Khalil, H. Xu, T. Berger, and G. L. Gerton, "New insights into sperm-zona pellucida interaction: involvement of sperm lipid rafts," Frontiers in Bioscience, vol. 12, no. 5, pp. 1748-1766, 2007.

[60] C. L. Trevio, C. J. Serrano, C. Beltrán, R. Felix, and A. Darszon, "Identification of mouse trp homologs and lipid rafts from spermatogenic cells and sperm," FEBS Letters, vol. 509, no. 1, pp. 119-125, 2001.

[61] S. Shadan, P. S. James, E. A. Howes, and R. Jones, "Cholesterol efflux alters lipid raft stability and distribution during capacitation of boar spermatozoa," Biology of Reproduction, vol. 71, no. 1, pp. 253-265, 2004.

[62] N. Kawano, K. Yoshida, T. Iwamoto, and M. Yoshida, "Ganglioside GM1 mediates decapacitation effects of SVS2 on murine spermatozoa," Biology of Reproduction, vol. 79, no. 6, pp. 1153-1159, 2008. 
[63] V. Selvaraj, A. Asano, D. E. Buttke et al., "Segregation of micron-scale membrane sub-domains in live murine sperm," Journal of Cellular Physiology, vol. 206, no. 3, pp. 636-646, 2006.

[64] V. Selvaraj, D. E. Buttke, A. Asano et al., "GM1 dynamics as a marker for membrane changes associated with the process of capacitation in murine and bovine spermatozoa," Journal of Andrology, vol. 28, no. 4, pp. 588-599, 2007.

[65] C. Dietrich, B. Yang, T. Fujiwara, A. Kusumi, and K. Jacobson, "Relationship of lipid rafts to transient confinement zones detected by single particle tracking," Biophysical Journal, vol. 82, no. 1, pp. 274-284, 2002.

[66] R. Ishitsuka, S. B. Sato, and T. Kobayashi, "Imaging lipid rafts," Journal of Biochemistry, vol. 137, no. 3, pp. 249-254, 2005.

[67] R. G. Parton, "Caveolae and caveolins," Current Opinion in Cell Biology, vol. 8, no. 4, pp. 542-548, 1996.

[68] E. J. Smart, G. A. Graf, M. A. McNiven et al., "Caveolins, liquid-ordered domains, and signal transduction," Molecular and Cellular Biology, vol. 19, no. 11, pp. 7289-7304, 1999.

[69] A. J. Travis, T. Merdiushev, L. A. Vargas et al., "Expression and localization of caveolin-1, and the presence of membrane rafts, in mouse and guinea pig spermatozoa," Developmental Biology, vol. 240, no. 2, pp. 599-610, 2001.

[70] P. V. Miranda, A. Allaire, J. Sosnik, and P. E. Visconti, "Localization of low-density detergent-resistant membrane proteins in intact and acrosome-reacted mouse sperm," Biology of Reproduction, vol. 80, no. 5, pp. 897-904, 2009.

[71] B. Razani, J. A. Engelman, X. B. Wang et al., "Caveolin-1 null mice are viable but show evidence of hyperproliferative and vascular abnormalities," Journal of Biological Chemistry, vol. 276, no. 41, pp. 38121-38138, 2001.

[72] B. Razani, X. B. Wang, J. A. Engelman et al., "Caveolin-2deficient mice show evidence of severe pulmonary dysfunction without disruption of caveolae," Molecular and Cellular Biology, vol. 22, no. 7, pp. 2329-2344, 2002.

[73] S. A. Stricker and M. Whitaker, "Confocal laser scanning microscopy of calcium dynamics in living cells," Microscopy Research and Technique, vol. 46, no. 6, pp. 356-369, 1999.

[74] S. Miyazaki, "Repetitive calcium transients in hamster oocytes," Cell Calcium, vol. 12, no. 2-3, pp. 205-216, 1991.

[75] S. Miyazaki and M. Ito, "Calcium signals for egg activation in mammals," Journal of Pharmacological Sciences, vol. 100, no. 5, pp. 545-552, 2006.

[76] S. Ken-Ichi, "Signal transduction of fertilization in frog eggs and anti-apoptotic mechanism in human cancer cells: common and specific functions of membrane microdomains," The Open Biochemistry Journal, vol. 2, pp. 49-59, 2008.

[77] M. Wilding and B. Dale, "Sperm factor: what is it and what does it do?" Molecular Human Reproduction, vol. 3, no. 3, pp. 269-273, 1997.

[78] K. Sakakibara, K. I. Sato, K. I. Yoshino et al., "Molecular identification and characterization of Xenopus egg uroplakin III, an egg raft-associated transmembrane protein that is tyrosine-phosphorylated upon fertilization," Journal of Biological Chemistry, vol. 280, no. 15, pp. 15029-15037, 2005.

[79] A. K. M. Mahbub Hasan, K. I. Sato, K. Sakakibara et al., "Uroplakin III, a novel Src substrate in Xenopus egg rafts, is a target for sperm protease essential for fertilization," Developmental Biology, vol. 286, no. 2, pp. 483-492, 2005.

[80] A. K. M. Mahbub Hasan, Z. Ou, K. Sakakibara et al., "Characterization of Xenopus egg membrane microdomains containing uroplakin Ib/III complex: roles of their molecular interactions for subcellular localization and signal transduction," Genes to Cells, vol. 12, no. 2, pp. 251-267, 2007.

[81] K. Miyado, G. Yamada, S. Yamada et al., "Requirement of CD9 on the egg plasma membrane for fertilization," Science, vol. 287, no. 5451, pp. 321-324, 2000.

[82] M. Tanigawa, K. Miyamoto, S. Kobayashi et al., "Possible involvement of CD81 in acrosome reaction of sperm in mice," Molecular Reproduction and Development, vol. 75, no. 1, pp. 150-155, 2008.

[83] C. Claas, C. S. Stipp, and M. E. Hemler, "Evaluation of prototype transmembrane 4 superfamily protein complexes and their relation to lipid rafts," Journal of Biological Chemistry, vol. 276, no. 11, pp. 7974-7984, 2001.

[84] E. Rubinstein, A. Ziyyat, M. Prenant et al., "Reduced fertility of female mice lacking CD81," Developmental Biology, vol. 290, no. 2, pp. 351-358, 2006.

[85] K. E. Runge, J. E. Evans, Z. Y. He et al., "Oocyte CD9 is enriched on the microvillar membrane and required for normal microvillar shape and distribution," Developmental Biology, vol. 304, no. 1, pp. 317-325, 2007.

[86] C. A. Ziomek and M. H. Johnson, "Cell surface interaction induces polarization of mouse 8-cell blastomeres at compaction," Cell, vol. 21, no. 3, pp. 935-942, 1980.

[87] M. Ohsugi, P. Zheng, B. Baibakov, L. Li, and J. Dean, "Maternally derived FILIA-MATER complex localizes asymmetrically in cleavage-stage mouse embryos," Development, vol. 135, no. 2, pp. 259-269, 2008.

[88] D. Solter and B. B. Knowles, "Monoclonal antibody defining a stage-specific mouse embryonic antigen (SSEA-1)," Proceedings of the National Academy of Sciences of the United States of America, vol. 75, no. 11, pp. 5565-5569, 1978.

[89] H. C. Gooi, T. Feizi, A. Kapadia, B. B. Knowles, D. Solter, and M. J. Evans, "Stage-specific embryonic antigen involves alpha 1 goes to 3 fucosylated type 2 blood group chains," Nature, vol. 292, pp. 156-158, 1981.

[90] R. Kannagi, E. Nudelman, S. B. Levery, and S. Hakomori, "A series of human erythrocyte glycosphingolipids reacting to the monoclonal antibody directed to a developmentally regulated antigen, SSEA-1," Journal of Biological Chemistry, vol. 257, no. 24, pp. 14865-14874, 1982.

[91] T. Feizi, "The antigens Ii, SSEA-1 and ABH are in interrelated system of carbohydrate differentiation antigens expressed on glycosphingolipids and glycoproteins," Advances in Experimental Medicine and Biology, vol. 152, pp. 167-177, 1982.

[92] B. A. Fenderson, U. Zehavi, and S. I. Hakomori, "A multivalent lacto-N-fucopentaose III-lysyllysine conjugate decompacts preimplantation mouse embryos, while the free oligosaccharide is ineffective," Journal of Experimental Medicine, vol. 160, no. 5, pp. 1591-1596, 1984.

[93] I. Eggens, B. Fenderson, T. Toyokuni, B. Dean, M. Stroud, and S. I. Hakomori, "Specific interaction between Lex and Lex determinants. A possible basis for cell recognition in preimplantation embryos and in embryonal carcinoma cells," Journal of Biological Chemistry, vol. 264, no. 16, pp. 94769484, 1989.

[94] T. Muramatsu and H. Muramatsu, "Carbohydrate markers of ES cells," Trends in Glycoscience and Glycotechnology, vol. 21, no. 120, pp. 197-208, 2009.

[95] L. Hamburger Shevinsky, B. B. Knowles, I. Damjanov, and D. Solter, "Monoclonal antibody to murine embryos defines a stage-specific embryonic antigen expressed on mouse embryos and human teratocarcinoma cells," Cell, vol. 30, no. 3, pp. 697-705, 1982. 
[96] R. Kannagi, S. B. Levery, F. Ishigami et al., "New globoseries glycosphingolipids in human teratocarcinoma reactive with the monoclonal antibody directed to a developmentally regulated antigen, stage-specific embryonic antigen 3," Journal of Biological Chemistry, vol. 258, no. 14, pp. 8934-8942, 1983.

[97] R. Kannagi, N. A. Cochran, F. Ishigami et al., "Stagespecific embryonic antigens (SSEA-3 and -4) are epitopes of a unique globo-series ganglioside isolated from human teratocarcinoma cells," EMBO Journal, vol. 2, no. 12, pp. 2355-2361, 1983.

[98] Y. U. Katagiri, K. Ohmi, C. Katagiri et al., "Prominent immunogenicity of monosialosyl galactosylgloboside, carrying a stage-specific embryonic antigen-4 (SSEA-4) epitope in the ACHN human renal tubular cell line-a simple method for producing monoclonal antibodies against detergentinsoluble microdomains/raft," Glycoconjugate Journal, vol. 18, no. 4, pp. 347-353, 2001.

[99] B. Sato, Y. U. Katagiri, K. Miyado et al., "Preferential localization of SSEA-4 in interfaces between blastomeres of mouse preimplantaion embryos," Biochemical and Biophysical Research Communications, vol. 364, no. 4, pp. 838-843, 2007.

[100] M. Comiskey and C. M. Warner, "Spatio-temporal localization of membrane lipid rafts in mouse oocytes and cleaving preimplantation embryos," Developmental Biology, vol. 303, no. 2, pp. 727-739, 2007.

[101] L. Cui, K. Johkura, F. Yue et al., "Spatial distribution and initial changes of SSEA-1 and other cell adhesion-related molecules on mouse embryonic stem cells before and during differentiation," Journal of Histochemistry and Cytochemistry, vol. 52, no. 11, pp. 1447-1457, 2004.

[102] M. T. Zilber, N. Setterblad, T. Vasselon et al., "MHC class II/CD38/CD9: a lipid-raft-dependent signaling complex in human monocytes," Blood, vol. 106, no. 9, pp. 3074-3081, 2005.

[103] T. Lebedeva, M. L. Dustin, and Y. Sykulev, "ICAM-1 costimulates target cells to facilitate antigen presentation," Current Opinion in Immunology, vol. 17, no. 3, pp. 251-258, 2005.

[104] D. Gratzinger, S. Canosa, B. Engelhardt, and J. A. Madri, "Platelet endothelial cell adhesion molecule-1 modulates endothelial cell motility through the small G-protein Rho," FASEB Journal, vol. 17, no. 11, pp. 1458-1469, 2003.

[105] S. Rajagopalan, V. Wachtler, and M. Balasubramanian, "Cytokinesis in fission yeast: a story of rings, rafts and walls," Trends in Genetics, vol. 19, no. 7, pp. 403-408, 2003.

[106] M. L. Niswonger and T. J. O'Halloran, "A novel role for clathrin in cytokinesis," Proceedings of the National Academy of Sciences of the United States of America, vol. 94, no. 16, pp. 8575-8578, 1997.

[107] N. J. Gerald, C. K. Damer, T. J. O'Halloran, and A. De Lozanne, "Cytokinesis failure in clathrin-minus cells is caused by cleavage furrow instability," Cell Motility and the Cytoskeleton, vol. 48, no. 3, pp. 213-223, 2001.

[108] B. Feng, H. Schwarz, and S. Jesuthasan, "Furrow-specific endocytosis during cytokinesis of zebrafish blastomeres," Experimental Cell Research, vol. 279, no. 1, pp. 14-20, 2002.

[109] M. M. Ng, F. Chang, and D. R. Burgess, "Movement of membrane domains and requirement of membrane signaling molecules for cytokinesis," Developmental Cell, vol. 9, no. 6, pp. 781-790, 2005. 

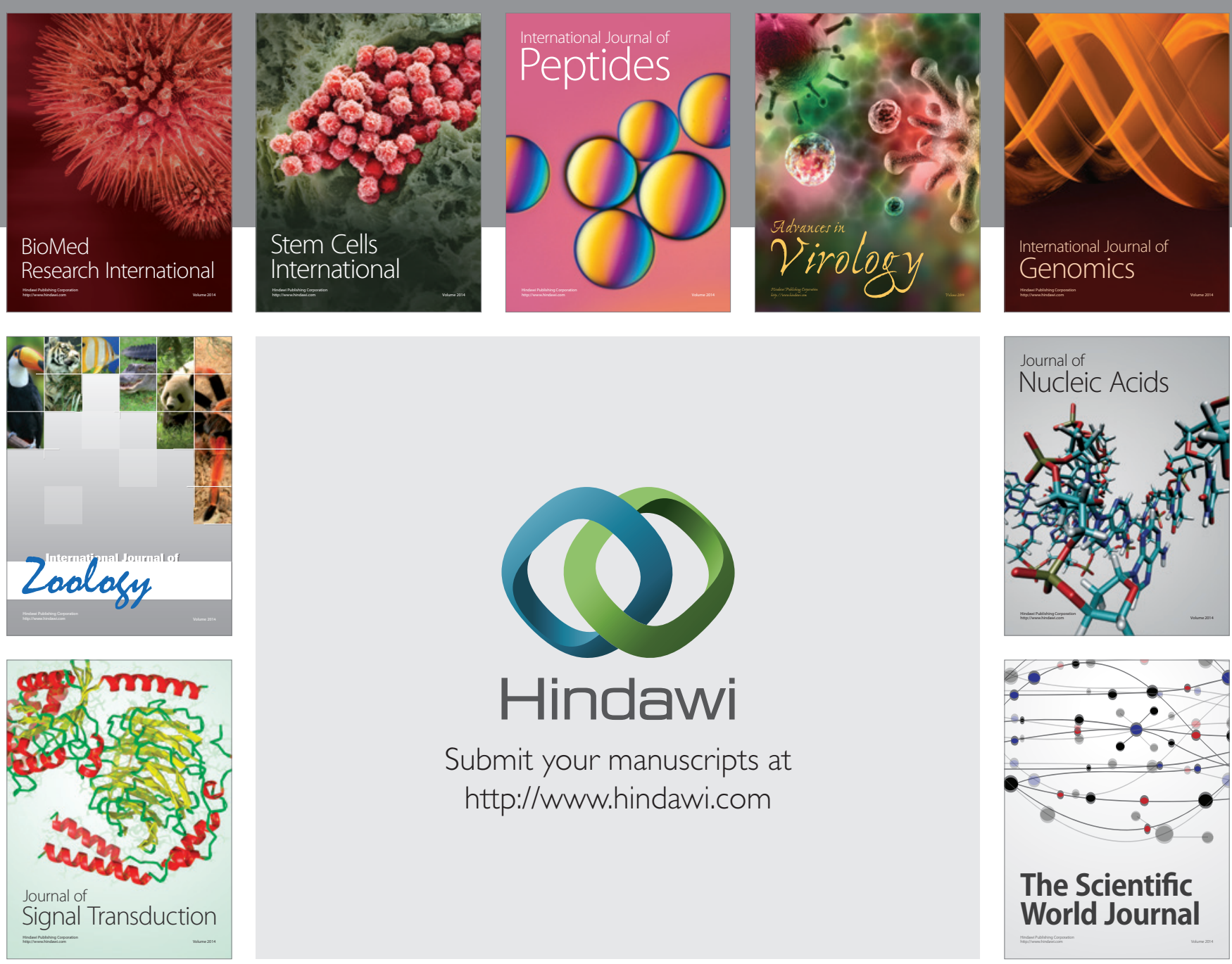

Submit your manuscripts at

http://www.hindawi.com
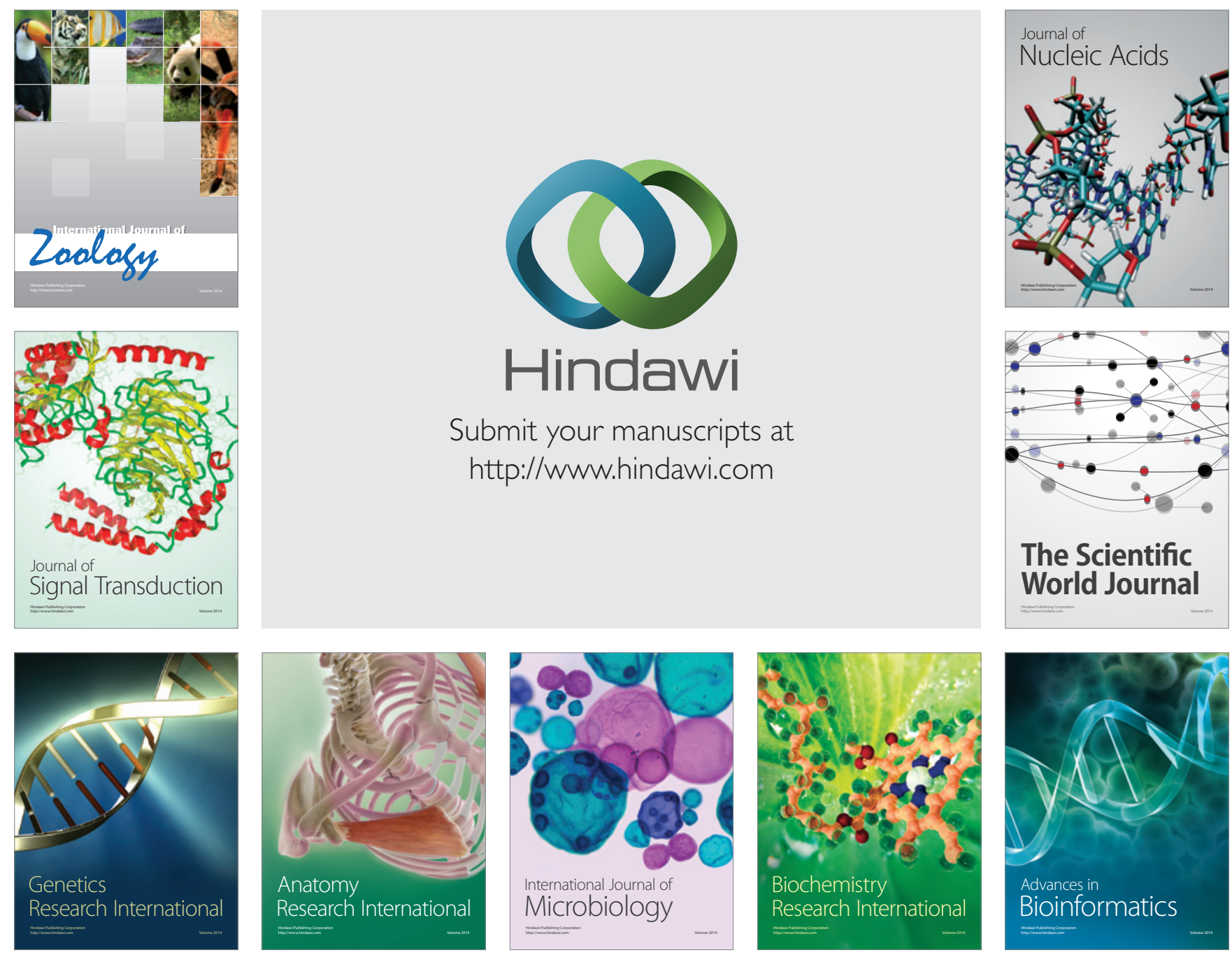

The Scientific World Journal
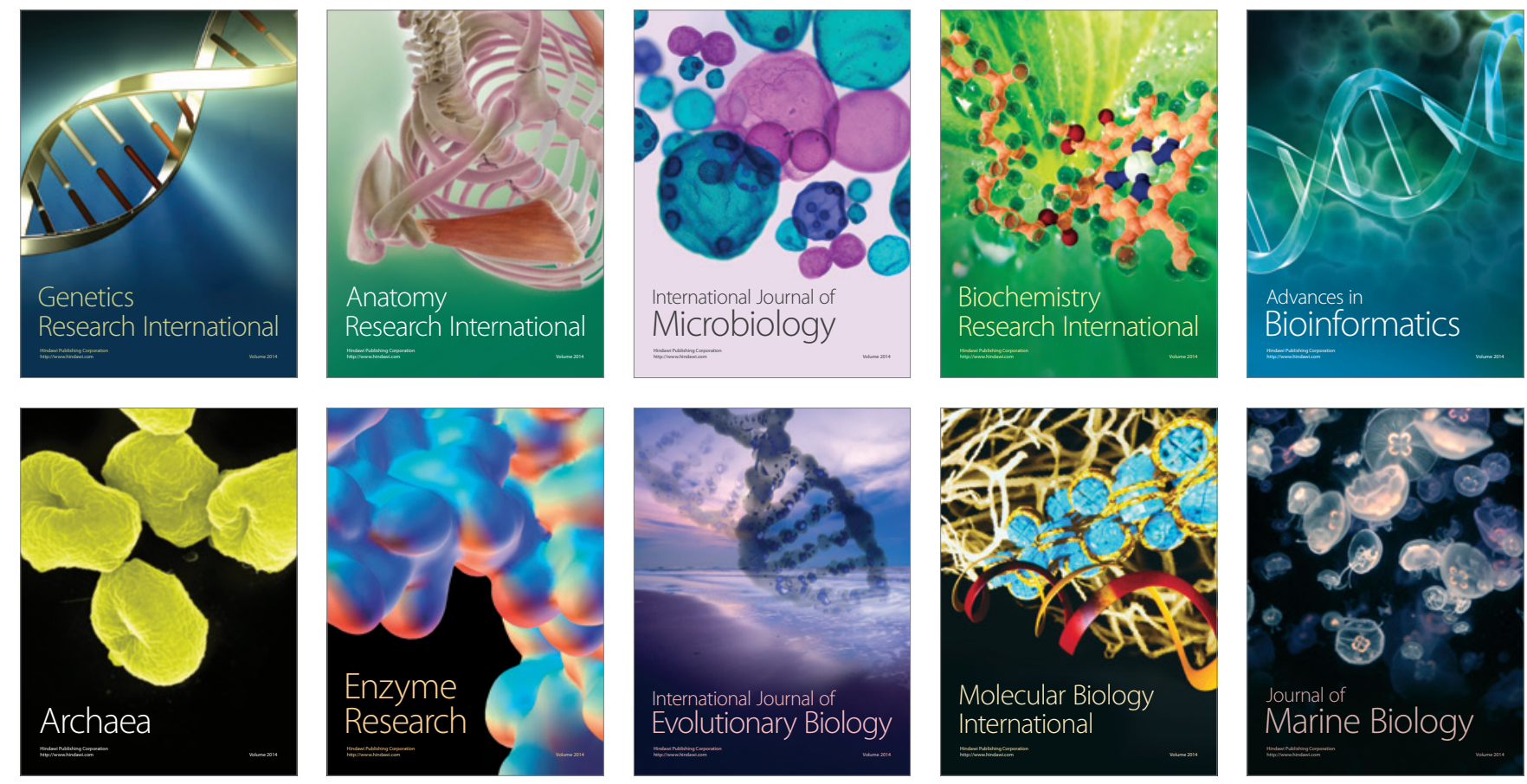